\title{
HLA Alloantibodies in Multiparous Women at Abidjan
}

\author{
N'guessan Koffi ${ }^{1}$, Akre Dagra Paul ${ }^{2}$, Dasse Sery Romuald ${ }^{1}$, Gobey Richard Arthur ${ }^{2}$, \\ Fizet Dominique $^{3}$, Seka Seka Joseph ${ }^{2}$, Sombo Mambo François ${ }^{1}$ \\ ${ }^{1}$ Department of Immunology-Hematology and Cancerology, Felix Houphouët Boigny University, Abidjan, Ivory Coast \\ ${ }^{2}$ Department of Immunology, Allassane Ouattara University, Bouake, Ivory Coast \\ ${ }^{3}$ Department of Cellular Immunology, French Blood Agency, Bordeaux, France
}

Email address:

koffi.nguessan@live.fr (N'guessan K.)

\section{To cite this article:}

N'guessan Koffi, Akre Dagra Paul, Dasse Sery Romuald, Gobey Richard Arthur, Fizet Dominique, Seka Seka Joseph, Sombo Mambo François. HLA Alloantibodies in Multiparous Women at Abidjan. International Journal of Immunology. Vol. 4, No. 6, 2016 , pp. 64-67. doi: $10.11648 / \mathrm{j} . \mathrm{iji} .20160406 .13$

Received: October 4, 2016; Accepted: November 23, 2016; Published: December 29, 2016

\begin{abstract}
Serum of multiparous women can contain HLA polyclonal antibodies which can be used as reagents for serological typing of HLA class I and class II. The aim of this study was to investigate an alloimmunization of multiparous women and to identify HLA polyclonal antibodies which could be useful as laboratory reagents in view of the future HLA unit of the Department of Immunology at Abidjan. In an experimental and analytic study, we screened HLA antibodies using microlymphocytotoxicity test on sera of 121 multiparous women aged from 18 to 70 years old, in apparent good health, transfused or no-transfused and with at least two parities. $37.19 \%$ of the multiparous women were alloimmunized. 13 women were sensitized to HLA class I, 18 to HLA class II and 14 were both sensitized to class I and class II. Specificity of the screened antibodies was identified at $17.78 \%$. HLA-B7 specificity (Class I) was $37.5 \%$ and class II specificity (HLA-DR4, DR7, DR13, DR13+14, DRw52) was $62.5 \%$. Specificity was evaluated by the correlation coefficient. For class I specificity correlation coefficients were ranged from 0.79 to 1 , while for class II specificities, correlation coefficients were ranged from 0.54 to 0.9. Screening of HLA antibodies on multiparous women at Abidjan was positive and specificities were determined. This enabled authors to the possibility of using multiparous women sera as a source of production of polyclonal antibodies for serological HLA typing in the HLA unit of the Department of Immunology at Abidjan.
\end{abstract}

Keywords: HLA Alloimmunization, Multiparous Women, Microlymphocytotoxicity, Ivory Coast

\section{Introduction}

The human leukocyte antigen (HLA) system represents a family of polymorphic cell surface molecules involved in the presentation of antigen to $T$ cells and thus play a central role in the induction and regulation of immune responses [1,2]. Specific HLA antibodies can be produced in any situation that exposes the host to the HLA alloantigen including pregnancy, transplantation transfusion and planned vaccination [3]. Anti-HLA antibodies can be identified in approximately $20 \%$ of pregnant women [4]. Multiparous women can be a source of producing HLA antibodies. The production, typing and identification of HLA antibodies are part of the routine laboratory tests performed for blood donors in developed countries [5]. Technological advances in the health sector of our country and organ transplant prospects dictate that we can routinely perform the serological typing of HLA antigens, hence the need of antiHLA specific antibody. Serum of multiparous women may contain anti-HLA polyclonal antibodies, which can be used as reagents for serological typing of HLA class I and class II [4]. The HLA test sera marketed, usually monoclonal antibodies are available in the market but at a very high cost. In contrast, HLA antibodies detected both in serum of multiparous women, polyclonal antibodies, are excellent reagents for HLA typing with a reasonable cost. The aim of our study was to screen HLA alloantibodies in multiparous and to identify exploitable antibodies as laboratory reagents, to the establishment of an HLA unit in the Department of Immunology of Cocody University Hospital at Abidjan. 


\section{Materials and Methods}

\subsection{Material}

One hundred twenty one women (121) in apparent good health, transfused or no-transfused were recruited at the obstetrics and Gynecology Department of Cocody University Hospital at Abidjan from January to June 2012. Their age ranged from 18 to 70 years. All participants had least 2 parities. Primiparous women, even with a known history of abortion were excluded from the study.

The reagents were consisted of 2 panels of 20 different cells (lymphocytes) each, from Bordeaux French Blood Agency including one panel for class I and one for Class II. A platelet pool "ripened" was also provided by Bordeaux French Blood Agency. Other reagents were used, including trypan blue $3 \%$, Hanks liquid (Seromed), plamagel (Rhone Poulenc), paraffin oil, liquid nitrogen, dithiothreitol (DTT) $0.01 \mathrm{mmol} / \mathrm{L}$ (Sigma), saturated cystine $0.02 \mathrm{mmol} / \mathrm{L}$ (Sigma), PBS buffer (Seromed).

The platform was consisted of plates Teresaki (Lab Nunc), a vending machine (self-DATTER ${ }^{\circledR}$ SERADOT CELL), an inverted microscope (Diavert-LEITZ®), a flow cytometer (Cytotron Absolute $\left.{ }^{\circledR}\right)$.

\subsection{Methods}

Patients were selected after informed consent. Peripheral blood was collected from them by venipuncture in sterile dry tubes. Screening and identification tests for antibodies were performed on sera obtained after centrifugation and decantation of the blood.

A first step was to screen anti-HLA class I and class II by microlymphocytotoxicity method based on the lysis of lymphocytes panel by specific HLA antibodies contained in the serum in presence of rabbit complement. Then the revelation was made from an inverted microscope by observing the dye (trypan blue) within lysed cells.

Then in sera, class I antibodies were removed by absorption on a ripened pooled platelets (rich in class I antigens).

A second stage was to identify antibodies class by 3 methods:

-Treatment of positive sera by the DTT (Dithiotreitol) which inactivates IgM antibody;

-Heat effect (The reaction was negative beyond $22^{\circ} \mathrm{C}$ if antibody was IgM. If it was $\operatorname{IgG}$, the reaction was positive regardless of the temperature: $4^{\circ} \mathrm{C}$ at $37^{\circ} \mathrm{C}$ );

-Flow cytometry with the labelling cells expressing HLA specificities by polyclonal HLA antibodies contained in the serum and its visualization by anti-IgG monoclonal antibodies or anti-IgM coupled to phycoerythrin.

\subsection{Statistical}

Data processing and analysis were obtained by EPI-INFO V5.0, SPSS-PC. We used the parametric tests (Student's test) when the data distribution was normal. Otherwise, non-parametric tests (Mann-Vithney-Wilcoxon) were preferred.

Correlation coefficients $\left(\mathrm{r}^{2}\right)$ were obtained using the software EPI-INFO V5.0, SPSS-PC. $\mathrm{r}^{2}$ evaluated strength of the relation between the anti-HLA antibody produced in immunized women and its antigenic specificity. The relation was low if $r^{2}$ was ranged in [0-0.25]; average, in [0.25-0.5]; strong, in [0.5-0.75]; and very strong, in [0.75-0.1].

\section{Results}

45 multiparous women (37.19\%) had been HLA immunized. Class II antibodies were predominant.

Table 1. Distribution of anti-HLA antibodies in multiparous women.

\begin{tabular}{lllll}
\hline immunized & \multicolumn{3}{l}{ unimmunized } \\
\hline HLA class & I & II & I+II & \\
\hline $\mathrm{N}(\%)$ & $13(10.74 \%)$ & $18(14.88 \%)$ & $14(11.57 \%)$ & $76(62.81 \%)$ \\
\hline
\end{tabular}

Table 2. Distribution of class I antibodies depending on the immunoglobulin class.

\begin{tabular}{llll}
\hline Isotypes & IgG & IgM & IgG+IgM \\
\hline $\mathrm{N}(\%)$ & $21(77.78 \%)$ & $5(18.52 \%)$ & $1(3.7 \%)$ \\
\hline
\end{tabular}

Specificity of HLA antibodies was identified at $17.78 \%$. HLA-B7 specificity (Class I) was $37.5 \%$ and class II specificity (HLA-DR4, DR7, DR13, DR13+14, DRw52) was $62.5 \%$. No anti-HLA-A specificity was found. Correlation coefficients $\left(\mathrm{r}^{2}\right)$ for class I specificity (HLA-B7) were ranged from 0.79 to 1 ; while for class II specificities, $\mathrm{r}^{2}$ were ranged from 0.54 to 0.9 .

Table 3. Specificity and correlation coefficients of anti-HLA antibodies produced.

\begin{tabular}{llll}
\hline HLA class & Specificity & $\mathbf{n}$ & $\mathbf{r}^{\mathbf{2}}$ \\
\hline I & HLA-B7 & 3 & 0.79 to 1 \\
& HLA-DR4 & 1 & 0.73 \\
& HLA-DR7 & 1 & 0.81 \\
II & HLA-DR13 & 1 & 0.73 \\
& HLA-DR13+14 & 1 & 0.9 \\
& HLA-DRW52 & 1 & 0.54 \\
\hline
\end{tabular}

\section{Discussion}

The HLA system is known to be the most polymorphic in humans [6]. The distribution and frequency of HLA antigens vary greatly among different ethnic groups and this diversity has been postulated to evolve under unique selective pressure in different geographical areas [7]. The complementmediated microlymphocytotoxicity technique has been used as the standard for serologic typing of HLA class I and class II antigens [8]. HLA typing sera are mainly obtained from multiparous alloimmunized women, and their HLA specificities are determined against a panel of lymphocytes with known HLA types. In mothers, several studies confirm the production of antibodies against paternal HLA antigens expressed by fetal cells because of their passage into the maternal circulation during pregnancy $[9,10]$. Production of HLA antibodies in the mother follows the dynamics of 
allogenic immune response. Paternal HLA molecules expressed by fetal cells that pass through the maternal bloodstream induce blast transformation of no histocompatible $\mathrm{CD} 4+$ which produce among other cytokines, IL-4 and IL-5 that stimulate production of antibodies by B lymphocytes and plasma cell progeny [11]. Our study revealed a fetal-maternal HLA alloimmunization frequency at $37.19 \%$. In a previous study on Ivorian women, an author had reported a lower rate of HLA immunization at $18.6 \%$ [12]. This difference could be explained by the evolution of knowledge on the HLA system and especially the most effective techniques currently used for serological typing. Most of the data of HLA sensitization in pregnancy were obtained by use of a complement-dependent cytotoxicity assay. In many cases, antibodies cannot be detected by complement-dependent cytotoxicity as their level fades in time [13]. Due to variation in immunization, a wide variation in the incidence of anti-HLA antibodies in the sera of pregnant women variation was ranged from $18 \%$ to $30 \%$ [13]. Detection of HLA antibodies by the Luminex screening test revealed higher frequencies. With Luminex, anti-HLA immunization was observed beyond $50 \%[13,14]$. The rate of HLA alloantibodies is increased with the number of pregnancies. The frequencies of lymphocytotoxic antibodies, HLA-ABC antibodies and HLA-DR antibodies, were studied in 66 women at delivery. They were, respectively, $18.2 \%$ and $9 \%$ in the first pregnancies, $27.3 \%$ and $4.5 \%$ in the second pregnancies, $50 \%$ and $27.3 \%$ in the multigravidous women (third pregnancy and more) [15]. Immunization frequency increased with the number of children, reaching $74 \%$ in women with $>2$ deliveries [14].

Analysis of the results depending on the HLA class showed that HLA class II antibodies were predominant. This predominance of HLA class II antibodies could be explained by the important influence of class II antigens on B cells activation therefore the allogenic antibody response through cooperation TCD4+ and B lymphocytes. Rather the capacity of class I molecules to induce allogenic antibody response is low [16]. The antibodies produced were predominantly IgG isotype. Some women had produced alloantibodies both IgM class and IgG class. These results were consistent with those reported in the literature $[17,18]$. HLA antibodies were usually $\operatorname{IgG}$ and rarely IgM [18]. Studies have been reported that normal pregnant women develop anti-HLA antibodies, mostly after 20-28 weeks of gestation [19]. Whether antibodies were of class I or class II, IgM or IgG isotype, HLA antibodies induced in vitro cytolysis. Detailed analysis of specificity of HLA antibodies in our study revealed only one specificity class I while 5 specificities class II. No specific HLA-A antiboby was identified in our study. Indeed, the predominance of sensitization in the HLA-B locus might be related to its larger polymorphism compared to the other HLA loci [20,21]. This negative result could be explained by the sample size. Also the frequency of HLA class I alleles and their linkage disequilibrium patterns differ significantly among human populations.

Study of the relationship between HLA class I antibodies and antigenic specificity reported correlation coefficients which were closed to 1 . These good correlation coefficients showed that it was possible to constitute anti-HLA test sera from good maternal sera for local original typing tray.

\section{Conclusion}

There was an anti-HLA alloimmunization in the population of women multiparous in Abidjan. HLA antibodies produced were predominantly class II specificities, IgG isotype and great specificities to HLA antigens. These antibodies could therefore serve as reagents for HLA typing in our future HLA unit of the Department of Immunology at Abidjan pending production of monoclonal anti-HLA antibodies. But first, studies of a larger sample both of Africans and particular of Ivorians were needful to establish panels including all African specificities.

\section{Acknowledgements}

We would like to thank Department of Cellular Immunology of Bordeaux French Blood Agency (France) for their technical assistance in realization of this study.

\section{References}

[1] Navarrete CV. Human Leucocyte antigens. In Practical transfusion medicine. Michael FM, Derwood HP. Blackwell publishing, Oxford 2002, pp 36-49.

[2] Murphey CL, Forsthuber TG. Trends in HLA antibody screening and identification and their role in transplantation. Expert Rev Clin Immunol. 2008; 4: 391-9.

[3] Mason Y, Heine U, Stuhmiller GM. Human Leukocyte antigens. In Immunohematology-principles and practice. Lippincott-Raven publishers, Philadelphia 1998, pp 376-379.

[4] Little A, Steven GE, Alejandro M. Histocompatibility. In: Post graduate haematlogy. Victor $\mathrm{H}$, Daniel C, Edward GD. Blackwell publishing, Massachusets 2005, pp 395-413.

[5] Kleinman S, Chan P, Robillard P. Risk associated with transfusion of celllular blood components in Canada. Tranfus Med Rev. 2003; 17: 120-62.

[6] Klein J, Sato A. The HLA system. First of two years. New Engl J Med. 2000; 343: 702-9.

[7] Choo SY. The HLA system: genetics immunology, clinical testing and clinical implications. Yonsei Med J. 2007; 48: 11-23.

[8] Terasaki PI, Mcclelland JD. Microdroplet assay of human serum cytotoxins. Nature 1964; 204: 998-1000.

[9] Prescott SL, Taylor A, Ropert J, Wahdan A, Noakes P, Thornton C, Dunstan J, Upham JW. Maternal reactivity to fetal alloantigens is related to newborn immune responses and subsequent allergic disease. Clin Exp Allergy 2005; 35 (4): 417-25.

[10] Tomicić M, Starcević M, Bux J, Zach V, Hundrić-Haspl Z, Drazić V, Grahovac B. Severe neonatal neutropenia due to anti-human leucocyte antigen B49 alloimmunization only: a case report. Transfus Med. 2003; 13 (4): 233-7. 
[11] Richard AG, Thomas JK, Barbara AO.-Réactions d'hypersensibilité.-In Immunologie, le cours de Janis Kuby. Richard AG, Thomas JK, Barbara AO. Dunod, Paris 2003, pp 395-421.

[12] Pene F, Sombo MF, Cabannes R. Immunisation foetomaternelle anti-HLA en Côte d'Ivoire. Ann Univ Abidjan 1970; 14: 191-6.

[13] Vilches M, Nieto A. Analysis of pregnancy-induced anti-HLA antibodies using luminex platform. Transplant Proc. 2015; 47 (9): 2608-10.

[14] Masson E, Vidal C, Deschamps M, Bongain S, Thevenin C, Dupont I, Rietmulher D, Pouthier F, Mongaillard G, Chabod J, Ferrand $\mathrm{C}$, Tiberghien $\mathrm{P}$, Rebibou JM. Incidence and risk factors of anti-HLA immunization after pregnancy. Hum Immunol. 2013; 74 (8): 946-51.

[15] Morin-Papunel L, Tiilikainen A, Hartkainen-Sorri AL. Maternal HLA immunization during pregnancy: presence of anti HLA antibodies in half of multigravidous women. Med Biol. 1984; 62 (6): 323-5.

[16] Colombani, J. "HLA: Fonctions immunitaires et applications médicales" John Libbey Eurotext. Paris 1993, pp 285.
[17] Houissa B, Abdelkefi S, Bouslama M, Naggara M, Zaier M, Hmida S, Yacoub S. The utility of class I HLA antibodies screening in Tunisian obstetric departement in order to select good HLA typing reagents. Ann Biol Clin. 2003; 61 (4): 4359.

[18] Rafoux C, Lepage V.-Polymorphisme sérologique de classe I. La série allélique A, B, C.-in HLA. Complexe Majeur d'Histocompatibilité de l'Homme, Jean Dausset, Marika PL. Flammarion Medecine Sciences. Paris 1989, pp 64-100.

[19] Umapathy S1, Shankarkumar A, Ramrakhiyani V, Ghosh K. Role of anti-human lymphocyte culture cytotoxic antibodies in recurrent spontaneous pregnancy loss women. J Hum Reprod Sci. 2011; 4 (1): 17-9.

[20] Dankers MK, Roelen DL, Korfage N, de Lange P, Witvliet M, Sandkuijl L, Doxiadis II, Claas FH. Differential immunogenicity of paternal HLA Class I antigens in pregnant women. Hum Immunol. 2003; 64: 600-6.

[21] Hönger G, Fornaro I, Granado C, Tiercy JM, Hösli I, Schaub S. Frequency and determinants of pregnancy-induced childspecific sensitization. Am J Transplant. 2013; 13: 746-53. 